\title{
Approach for Polishing Diamond Coated Complicated Cutting Tool: Abrasive Flow Machining (AFM)
}

\author{
Xin-Chang Wang ${ }^{*}$ (D), Cheng-Chuan Wang, Chang-Ying Wang and Fang-Hong Sun
}

\begin{abstract}
Lower surface roughness and sharper cutting edge are beneficial for improving the machining quality of the cutting tool, while coatings often deteriorate them. Focusing on the diamond coated WC-Co milling cutter, the abrasive flow machining (AFM) is selected for reducing the surface roughness and sharpening the cutting edge. Comparative cutting tests are conducted on different types of coated cutters before and after AFM, as well as uncoated WC-Co one, demonstrating that the boron-doped microcrystalline and undoped fine-grained composite diamond coated cutter after the AFM (AFM-BDM-UFGCD) is a good choice for the finish milling of the 6063 Al alloy in the present case, because it shows favorable machining quality close to the uncoated one, but much prolonged tool lifetime. Besides, compared with the micro-sized diamond films, it is much more convenient and efficient to finish the BDM-UFGCD coated cutter covered by nano-sized diamond grains, and resharpen its cutting edge by the AFM, owing to the lower initial surface roughness and hardness. Moreover, the boron incorporation and micro-sized grains in the underlying layer can enhance the film-substrate adhesion, avoid the rapid film removal in the machining process, and thus maximize the tool life (1040 $\mathrm{m}$, four times more than the uncoated one). In general, the AFM is firstly proposed and discussed for post-processing the diamond coated complicated cutting tools, which is proved to be feasible for improving the cutting performance
\end{abstract}

Keywords: Abrasive flow machining, Diamond coated complicated cutting tool, Surface roughness, Radius of the cutting edge, Machining quality, Tool lifetime

\section{Introduction}

Various types of aluminum ( $\mathrm{Al})$ alloys are used in many industrial fields, such as the aerospace industry, automotive industry, cable industry, as a result of the nice mechanical and technological properties, such as the high tensile strength, high strength to weight ratio, favorable corrosion resistance, nice castability and machinability [1]. Particularly, with the flourishing development of the cell phone industry, $\mathrm{Al}$ alloy phone shells gradually replace those made of the plastic and stainless steel [2], for instance, shells of the distinguished iPhone are made of the anodized $6063 \mathrm{Al}-\mathrm{Mg}$ alloy. In business applications, the customer preference puts forward

*Correspondence: wangxinchangz@163.com

School of Mechanical Engineering, Shanghai Jiao Tong University,

Shanghai 200240, China extremely high requirements in the surface quality of the phone shells, which can be obtained by milling and subsequent polishing. Due to the very large manufacturing batch for the phone shells, it is believed that the production cost may sharply rise with increasing the process, so it is of great significance to accomplish the machining only by milling, or milling and simple polishing processes. Al alloys perform good machinability owing to the low hardness, favorable strength and relatively high thermal conductivity, while have too high ductility, and the ductility will further increase with the temperature owing to the low melting point and the inferior high-temperature stability. As a result, the $\mathrm{Al}$ alloys have a strong tendency to stick to the cutting tool and to form build-up edges when machined. These build-up edges can severely affect surface finish and even remove small portions of 
the tool when it intermittently breaks away [3], and thus both the machining quality and the tool life deteriorate.

The chemical vapor deposition (CVD) diamond film is attractive as an ideal coating for excellent characteristics, such as the high hardness, favorable wear resistance, low friction coefficient, high thermal conductivity, low thermal expansion coefficient and excellent chemical stability $[4,5]$. It is demonstrated that during the machining processes of the $\mathrm{Al}$ alloy workpieces, especially under the circumstance of the rough machining, the deposition of diamond films on the cobalt cemented tungsten carbide (WC-Co) milling cutters can prolong the working lifetime significantly, and improve the machining quality to some extent, because the excellent tribological properties of the diamond film can reduce the adhesion between the cutter and workpiece [6]. However, for the finish machining, since the cutting depth is relatively small, it is supposed that the optimal-designed uncoated WC-Co milling cutters can meet the requirement of the machining quality during their life cycles, but one drawback is that they wear out rapidly, followed by the deterioration of the machining quality. The employment of the turning or milling cutters made of the monocrystalline diamond is believed as the best choice for finish machining $\mathrm{Al}$ alloy workpieces, regardless of the cost, which can be directly used for mirror finishing $[7,8]$. It is another option to adopt the polycrystalline diamond (PCD) as the cutting edges $[9,10]$, the wear resistance of which is undoubtedly much higher than that of WC-Co, while lower than those of the monocrystalline diamond and CVD diamond film. This is because the PCD is composed of not only diamond crystals but also some metallic bonding phases. Moreover, for either the monocrystalline diamond or $\mathrm{PCD}$, it is rather difficult to form milling cutters with complicated shapes. Consequently, prolonging the tool life and guaranteeing the long-time machining quality with low cost are main aims of depositing diamond films on milling cutters.

The pretreatment that is essential for depositing diamond films on the $\mathrm{WC}$-Co substrate [11], as well as the coverage of the film will both change the geometry of the cutter that is optimal-designed for finish-milling $\mathrm{Al}$ alloys, especially the radius of the cutting edge. Due to the fact that the small radius of the cutting edge often means the small cutting force and the improved machining quality $[12,13]$, and the passivation of the edge probably deteriorate the machining quality. Therefore, how to alleviate the passivation, or how to resharpen the cutting edge becomes imperative.

By reason of nodular or granular growth morphologies of the diamond films, the surface roughness also increases after the diamond growth. The low surface roughness of the coated rake face is also beneficial for good machining performance, including the surface finish of as-machined workpiece, the tool wear and chip morphology [1]. Some reports have addressed the polishing of the diamond coated tools [14], demonstrating the improvement in surface finish of Al-Si alloy [15], the counterbalance of the polishing for edge-rounding/ passivation effects of as-deposited diamond film on the cutting edge [16], the improvement in the edge sharpness [17]. However, most of the polishing methods are not suitable for finishing complicated surfaces of milling cutters. By contrast, the abrasive flow machining (AFM), known as a novel way for polishing complicated surfaces, is supposed as an effective solution for this problem. It is found that for high speed steel (HSS) and WC-Co cutting tools, in the preparation of the cutting edge by the AFM, the radius of the cutting edge can be actually controlled by adjusting the particle size as well as the volume ratio of the abrasive paste $[18,19]$.

In order to efficiently polish the diamond film, the initial surface roughness should be reduced as much as possible, and the surface hardness can be reasonably reduced to an acceptable level. The tool lifetime of the milling cutter is another pivotal factor to evaluate its performance, which is dependent on not only the surface hardness and the wear resistance but also the film-substrate adhesion, because the film removal acts as the main failure mode in applications of diamond coated cutting tools [20, 21]. It is recognized that the adhesion is related to the residual stress [22], and it is indeed proved that the integral wear behavior and the working lifetime of several diamond coated components are obviously affected by the adhesion $[23,24]$, especially for the WC-Co substrate, because the Co can promote the graphitization and apparently deteriorate the adhesion [25]. Some pretreatment techniques and deposition methods are proposed to enhance the adhesion, such as the alkali-acid pretreatment, microwave oxidation, energy ion irradiation, ion implantation and interlayers [26-29], which however can either cause voids generating or require more complex techniques. In addition, the boron-doped diamond (BDD) film can well adhere to the WC-Co and $\mathrm{SiC}$ substrates and perform much better wear behavior and elongated working lifetime $[23,24,30,31]$. Associated with the present study, it is of great significance to clarify effects of AFM on the performance of the undoped diamond film and the BDD film, either micro-crystallized or fine-grained, and the final optimal film type can be accordingly determined.

In this study, optimal-designed WC-6 wt.\%Co milling cutters with regular WC grain size were selected as the substrates for depositing varieties of hot filament CVD (HFCVD) diamond films on, including four monolayer films, i.e., the undoped micro-crystalline diamond (UMCD) film, the undoped fine-grained diamond 
(UFGD) film, the boron-doped micro-crystalline diamond (BDMCD) film, the boron-doped fine-grained diamond (BDFGD) film, and one high-performance composite diamond film, i.e., the boron-doped microcrystalline and undoped fine-grained composite diamond (BDM-UFGCD) film. AFM was used for modifying the surface smoothness and radii of cutting edges. Effects of the AFM on the performance of diamond coated milling cutters were further studied by cutting tests.

\section{Experimental Details}

\subsection{Substrates and Uncoated Milling Cutters}

For the determined workpiece (6063 Al alloy), a type of special-designed flat milling cutter was selected, as shown in Figure 1. Structural parameters of this milling cutter were as follows: three-edge, hilt diameter $D=10$ $\mathrm{mm}$, total length $L=75 \mathrm{~mm}$, edge diameter $d=10 \mathrm{~mm}$, edge length $l=30 \mathrm{~mm}$, helix angle $\beta=45^{\circ}$, rake angle of the peripheral cutting edge $\gamma_{o}=30^{\circ}$, relief angle of the peripheral cutting edge $\alpha_{o}=15^{\circ}$, radius of the peripheral cutting edge $r=0.01-0.02 \mathrm{~mm}$, with edge-lines on flank faces.

With regard to the substrate, the WC-Co was selected. The Co can promote the graphitization and deteriorate the adhesive strength of as-deposited diamond film. Although the higher Co content in the substrate could provide higher toughness for the milling cutter, the WC$6 \mathrm{wt} . \%$ Co was still the most appropriate for depositing CVD diamond films on. Besides, the WC-Co materials with fine $\mathrm{WC}$ grains $(<0.5 \mu \mathrm{m})$ performed superior mechanical properties, and cutting edges are much easier to be sharpened, but the adhesion of the diamond film on these substrates was relatively lower, mainly due to the inferior mechanical bonding between the diamond and fine WC grains. So the WC-6wt.\%Co with the regular WC grain size (about $0.5-1.5 \mu \mathrm{m}$ ) was finally fixed. The uncoated milling cutter made of such the material

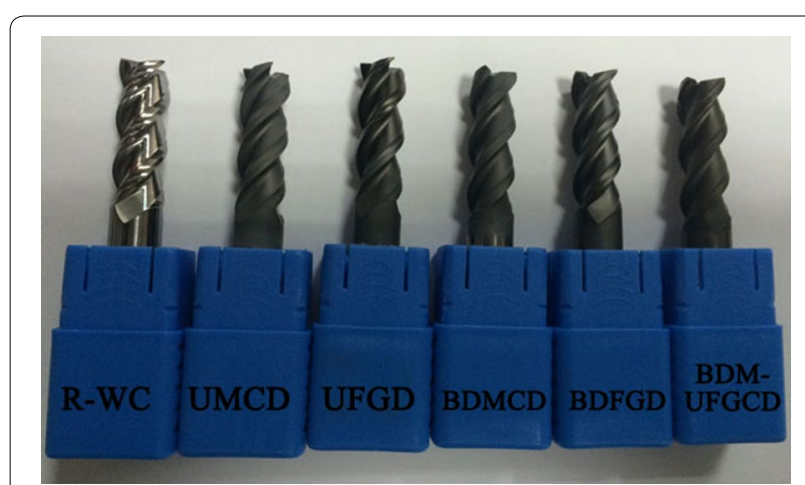

Figure 1 Photographs of the uncoated and different diamond coated milling cutters
(R-WC) had a radius of the peripheral cutting edge $r$ of $0.02 \mathrm{~mm}$. Moreover, in cutting tests, the uncoated milling cutter made of the WC-8wt.\%Co material with the small WC grain size $(<0.5 \mu \mathrm{m})$ (F-WC) was also used as the contrast specimen, which had an extremely small $r$ below $0.01 \mathrm{~mm}$.

The surface roughness $R_{a}$ values of both the rake and flank faces (the edge lines) of the uncoated milling cutters were measured by confocal microscopy (CM, Zeiss Axio CSM700), adopting a scanning length of about $50 \mu \mathrm{m}$. The radii of the peripheral cutting edges $r$ were approximately measured based on cross-sectional morphologies of the cutting-off milling cutters observed adopting the field emission scanning electron microscopy (FESEM, Zeiss ULTRA55). Each of the $R_{a}$ or the $r$ value was calculated by averaging five values obtained on five different positions, similarly hereinafter.

\subsection{Preparations of Diamond Coated Milling Cutters}

Before the deposition of any type of the diamond film, the WC-Co milling cutter was firstly pretreated by typical alkali-acid two-step pretreatment technique in order to roughen the deposited surfaces (mainly the etching effect of the Murakami alkali solution) and remove the cobalt element on or close to the surface (the etching effect of the acid solution), and thus enhance the nucleation density and alleviate the graphitization effect in the nucleation and growth processes of the diamond as much as possible [32]. Afterwards, the pretreated surfaces were ground with the diamond grits $(0.5-1 \mu \mathrm{m})$ for removing the loose layers on the etched surface and enhancing the nucleation density.

Diamond films were deposited on the pretreated milling cutters in a home-made HFCVD vacuum reactor, using the mixture of the acetone and hydrogen as the basic reactant gas. During the growth process of the BDD film, the acetone pre-mingled with a minuscule amount of trimethyl borate $\left[\left(\mathrm{CH}_{3} \mathrm{O}\right)_{3} \mathrm{~B}\right]$ was employed as the carbon source instead of pure acetone. The typical filament arrangement for fabricating diamond coated complicated cutting tools could refer to our pervious investigation [33]. Deposition parameters for the diamond nucleation and the growth of the four typical types of mono-layer diamond films were listed in Table 1, where the filament height $h_{f}$ was defined as the vertical distance between the tool nose and filament, minus representing that the filament was below the tool nose. A nucleation stage of 30 min was adopted at the initial stage of the deposition process of any type of the diamond film, with a view to obtaining relatively higher nucleation density for heteroepitaxy [34]. The mechanical properties and cutting performance of the diamond coated cutting tools and some other components were all closely associated with 
Table 1 Deposition parameters for synthesizing typical types of mono-layer diamond films

\begin{tabular}{|c|c|c|c|c|c|}
\hline & Nucleation & UMCD & UFGD & BDMCD & BDFGD \\
\hline Flux of $\mathrm{H}_{2} Q_{H}(\mathrm{~mL} / \mathrm{min})$ & & & 1100 & & \\
\hline Flux of acetone $Q_{A c e}(\mathrm{~mL} / \mathrm{min})$ & & & 20 & & \\
\hline $\mathrm{B} / \mathrm{C}$ atomic ratio $A R(\mathrm{ppm})$ & 0 & 0 & 0 & 4500 & 4500 \\
\hline Pressure $p(\mathrm{~Pa})$ & 1600 & 4000 & 1300 & 4000 & 1300 \\
\hline Filament diameter $D_{f}(\mathrm{~mm})$ & & & 0.6 & & \\
\hline Filament length $I_{f}(\mathrm{~mm})$ & & & 150 & & \\
\hline Filament separation $s_{f}(\mathrm{~mm})$ & & & 36 & & \\
\hline Filament height $h_{f}(\mathrm{~mm})$ & & & -6 & & \\
\hline Filament temperature $T_{s}\left({ }^{\circ} \mathrm{C}\right)$ & & & $2100 \pm 100$ & & \\
\hline Substrate temperature $T_{s}\left({ }^{\circ} \mathrm{C}\right)$ & & & $850 \pm 50$ & & \\
\hline Growth duration $t_{g}(h)$ & 0.5 & 12 & 9 & 11 & 8 \\
\hline
\end{tabular}

the film thickness $[6,30,35,36]$, and there were distinct differences between the growth rates of the various types of diamonds [37-40]. Therefore, the different growth durations were adopted for depositing different films of similar thicknesses. For the BDM-UFGCD film, the growth durations for the BDMCD and PFGD layers were respectively determined as $6 \mathrm{~h}$ and $4 \mathrm{~h}$.

Surface and cross-sectional morphologies of diamond films were all observed by the FESEM, and diamond ingredients were characterized by the Raman spectroscopy (XploRA, Horiba Jobin Yvon). For demonstrating the influences of the pretreatment and diamond growth on the surface roughness value and the radius of the cutting edge, after either the pretreatment or the growth processes, both the parameters were also measured according to the same techniques applied for the uncoated specimens.

\subsection{Abrasive Flow Machining}

In order to efficiently polish the diamond coated milling cutters by the AFM, a jig was designed firstly, as plotted in Figure 2(a). A commercial AFM apparatus (XINFENG BN100) was applied, using special-formulated polishing paste for machining the diamond film. The paste was constituted by the colloidal resin carrier, ultra-hard diamond particles (400 mesh), lubricant and adherent agent, as shown in Figure 2(b). During the AFM processes, the jig and the milling cutter were placed vertically in the apparatus, then the polishing paste moved up and down through holes of the jig under a pressure of $15 \mathrm{MPa}$. The paste could fill the space around the milling cutter in the jig, and thus efficiently polished its peripheral surface. It should be emphasized that the dowel was made of a screw, the upper surface of which must be at the same height of the upper surface of the upper cover for avoiding the unwanted deformation and even fracture

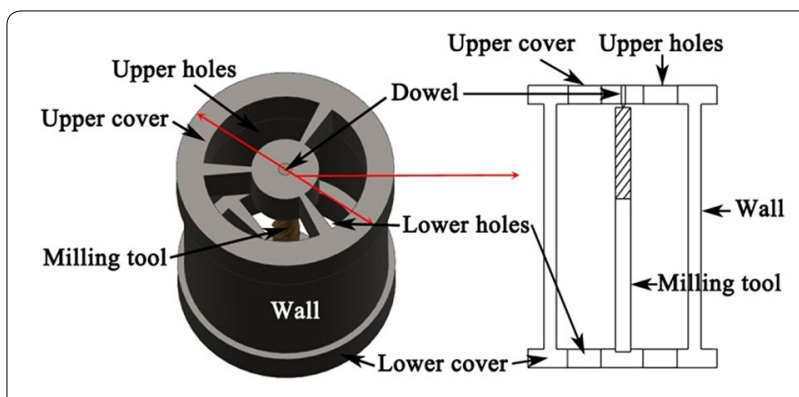

a

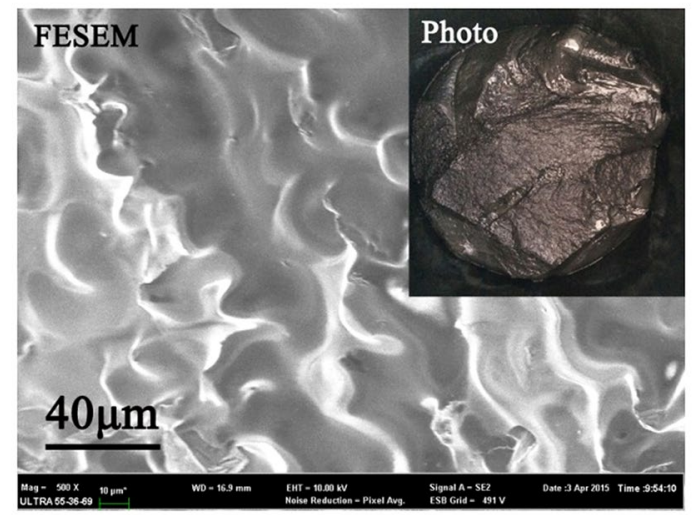

b

Figure $\mathbf{2}$ a As-designed jig and $\mathbf{b}$ the special-formulated polishing paste for abrasive flow machining the diamond coated milling cutters

of the dowel, upper cover and the milling cutter caused by the small load-bearing area under the initial pressure. Besides, the apex of the tighten dowel should contact the central point of the milling cutter under a contact pressure as small as possible, for either limiting the waggle of the cutter or alleviating the damage to its end edges. During the AFM process, the main input parameters included the cycle times, the pressure and the concentration of 
Table 2 The elementary composition of the 6063 Al alloy workpiece

\begin{tabular}{llllll}
\hline Element & Al & Mg & Si & Fe & Others \\
\hline Percentage $m(w t \%)$ & 99.24 & 0.49 & 0.21 & 0.11 & 0.17 \\
\hline
\end{tabular}

Table 3 Cutting parameters adopted in the cutting tests

\begin{tabular}{ll}
\hline Parameter & Value \\
\hline Rotational speed $n(\mathrm{r} / \mathrm{min})$ & 10000 \\
Milling speed $v(\mathrm{~m} / \mathrm{min})$ & 314 \\
Milling width $a_{e}(\mathrm{~mm})$ & 0.08 \\
Milling depth $a_{p}(\mathrm{~mm})$ & 7.5 \\
Feed rate $f(\mathrm{~mm} / \mathrm{min})$ & 1200 \\
Lubrication & Oil-base \\
& suspen- \\
& sion
\end{tabular}

the diamond particles in the polishing paste [41]. In this study, the latter two were determined, so the former was the only control variable for different specimens.

\subsection{Cutting Tests: Peripheral Finish-Milling the $6063 \mathrm{Al}$ Alloy}

Due to the limitation of the AFM and the jig adopted in the present study, only peripheral surfaces and cutting edges of the diamond coated milling cutters were effectively polished, so the machining mode of the cutting tests was determined as the peripheral finish-milling, which just made use of the peripheral cutting edges of the milling cutters. Moreover, for the varieties of other types of cutting tools, such as the face milling cutter, the ball end milling cutter and the driller, corresponding appropriate jigs should be specially designed during the subsequent further researches. In the present study, all the cutting tests were carried out on a machining center (Hurco VMX42), using the $6063 \mathrm{Al}$ alloy plates $(300 \mathrm{~mm} \times 200 \mathrm{~mm} \times 6 \mathrm{~mm}$ ) as workpieces. As detected by energy dispersive spectroscopy (EDS), the elementary composition of such the workpiece was listed in Table 2. A set of definite cutting parameters as stated in Table 3, which were the common parameters for peripheral finish-milling the $6063 \mathrm{Al}$ alloy, were adopted.

During the cutting test, the dynamometer (Kistler-9272) was used to measure the cutting force real timely. The surface roughness values of as-machined workpieces were measured by a portable surface roughometer (MITUTOYO SJ-210). The tool failure appeared as the reduction of the machining quality, so the tool lifetime was approximately defined as the milling length when the machining quantity deteriorates, specifically, as the surface roughness $R_{z}$ value of the workpiece reaches $1.6 \mu \mathrm{m}$. Besides, several typical failure modes were presented, based on worn morphologies examined by the FESEM.

\section{Results and Discussions}

\subsection{Characterizations on As-Prepared Milling Cutters}

It is described above that the uncoated milling cutters are named as R-WC and F-WC, respectively referring to the milling cutters made of WC-6wt.\%Co with the regular and small WC grain sizes. Besides, as-fabricated diamond coated milling cutters are named based on the type of the selected diamond film, i.e., UMCD, UFGD, BDMCD, BDFGD and BDM-UFGCD, while the diamond coated milling cutters after AFM are named by adding a prefix of AFM, for example, AFM-UMCD. Besides, the $\mathrm{R}$-WC milling cutter after the pretreatment but before the deposition of the diamond film is also characterized in some respects, which is named as P-R-WC.

Photographs of uncoated and different diamond coated milling cutters are all listed in Figure 1. By visual inspections, it can be judged that the uncoated milling cutter (R-WC) is bright and smooth, while the brightness and smoothness of all the diamond coated milling cutters are significantly reduced. Besides, obvious differences also exist between the colors and lusters of as-deposited diamond films with micro- and nano-sized grains on the film surfaces, the former presenting gray colors and pale reflections and the latter presenting relatively shiny black colors.

Surface and cross-sectional morphologies of the five different types of diamond coated milling cutters before AFM, and the surface morphology of the R-WC are all shown in Figure 3. It is firstly proved that different diamond films of similar thicknesses $(9-11 \mu \mathrm{m})$ are indeed deposited on R-WC substrates by controlling the growth time. Besides, typical surface features related to the micro-sized and nano-sized diamond films appear, well in accordance with the previous study.

Both the UMCD and BDMCD films show micro-sized diamond grains with well-defined shapes, and the boron doping technique can slightly reduce the grain size. The average grain size of the UMCD film is $2-4 \mu \mathrm{m}$, while that of the BDMCD film is $1-3 \mu \mathrm{m}$. Attributed to the distinct crests and valleys of the shaped diamond grains, the surface roughness $R_{a}$ values on the rake and flank faces of the UMCD coated milling cutter are as high as 242.54 and $267.91 \mathrm{~nm}$, and those of the BDMCD coated ones are 237.15 and $252.4 \mathrm{~nm}$. Cauliflower-like nodules composed of the dense nano-sized diamond grains (20-500 $\mathrm{nm}$ ) appear on the surfaces of not only the UFGD and BDFGD films, but also the BDM-UFGCD film with a surface UFGD layer. The nodules are more densely packed 


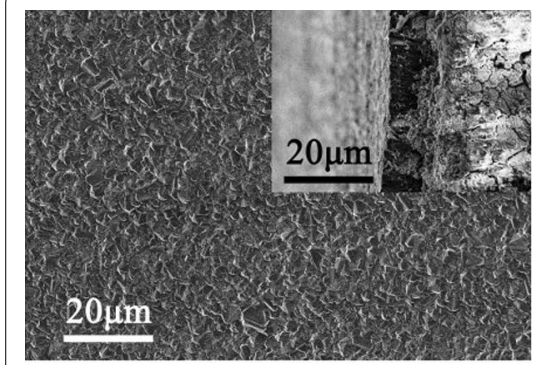

$\mathbf{a}$

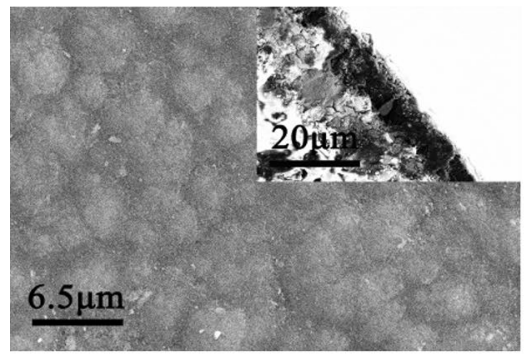

d

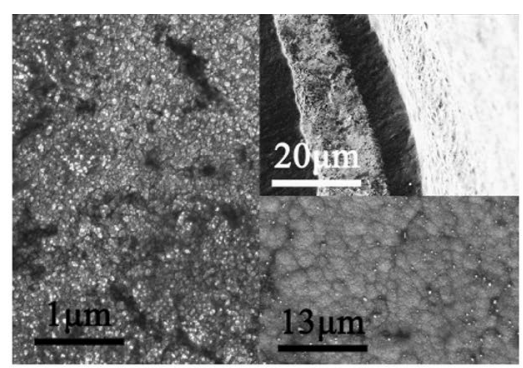

b

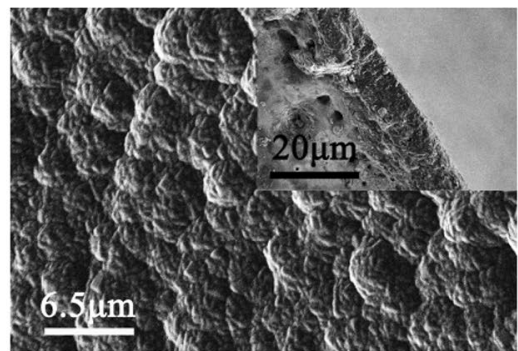

e

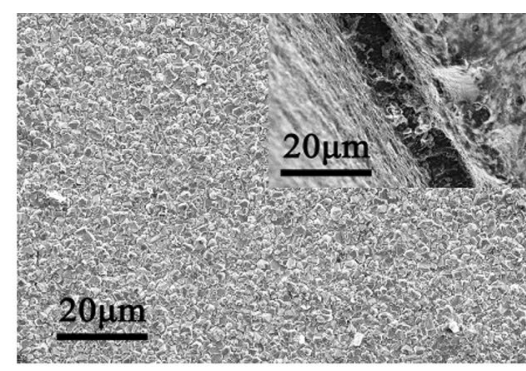

c

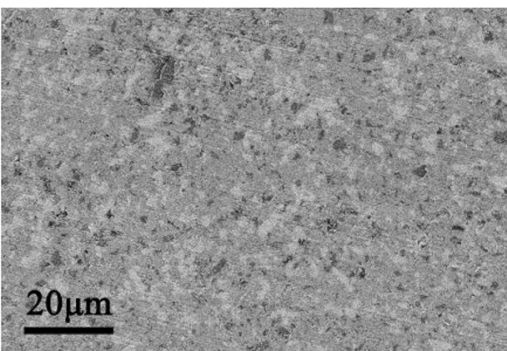

f

Figure 3 FESEM micrographs of a PMCD, b PFGD, c BDMCD, d BDFGD and e BDM-PFGCD coated milling cutters before AFM, and $\mathbf{f}$ the uncoated milling cutter (R-WC)

and form larger, shallower dome-like protrusions, resulting in a relatively lower surface roughness. Nevertheless, it is found that nano-sized diamond grains of the BDMUFGCD film are larger than those of the single-layer FGD films, which can be distinguished from cauliflowerlike shapes in the FESEM micrographs with lower amplification factors. As a result, the surface roughness $R_{a}$ values on the rake and flank faces of the UFGD coated cutter reach 142.36 and $161.94 \mathrm{~nm}$, and those of the BDFGD coated one are 137.22 and $167.54 \mathrm{~nm}$, but those of the BDM-UFGCD coated one are a little higher, which are 162.9 and $186.22 \mathrm{~nm}$. As a comparison, the uncoated milling cutter (R-WC), which is elaborately ground, performs a rather smooth surface. The surface roughness $R_{a}$ values on its rake and flank faces are as low as 61.47 and $73.29 \mathrm{~nm}$, respectively, and those for the F-WC are 58.72 and $65.44 \mathrm{~nm}$.

The Raman spectra of the different diamond coated milling cutters before and after the Gauss-Lorentz (G-L) deconvolution are plotted in Figure 4, indicating distinct features related to micro- and nano-sized diamond grains.

For the film surfaces constituted of micro-sized diamond grains, pronounced peaks located around 1332.4/ $\mathrm{cm}$ corresponding to the $\mathrm{sp}^{3}$ diamond phase dominate in their Raman spectra, fully demonstrating the high polycrystalline diamond purity. On the contrary, the purities of the film surfaces comprised of the nanosized diamond grains significantly reduces, manifesting as the enhancement of non-diamond peaks, especially the broad peaks around $1580 / \mathrm{cm}$ corresponding to the graphitic phase ( $G$ bands). Besides, the peaks around $1200 / \mathrm{cm}$ in the Raman spectra of the boron-doped film surfaces are the typical features related to the boron doping. Specially, for the BDM-UFGCD film, because the Raman can detect mostly the chemical characters of the film surface (the UFGD layer), significant nondiamond peaks exist in its Raman spectrum. However, compared with the single-layer UFGD film, the full width at half maximum (FWHM) of the $\mathrm{sp}^{3}$ diamond peak is smaller, indicating that the diamond purity on the surface of the composite film is a little higher, owing to the effect of the BDMCD layer beneath the surface UFGD layer. It is rather difficult to measure the hardness of the diamond film deposited on the complicated milling cutter, but in our previous study, on the planar WC- 6 wt.\%Co substrates, it is proved that the surface hardness decreases when the grain size changes from micro to nano, mainly as a result of the deteriorated film quality, while the hardness of the composite diamond film, although with nano-sized diamond grains on the surface, is higher than that of the UFGD film, due to the reinforcement effect of the micro-sized diamond grains.

The influences of the pretreatment and the coverage of the diamond films on the radius of the peripheral cutting edge are also illuminated, based on the measurements on the FESEM cross-sectional morphologies of the 


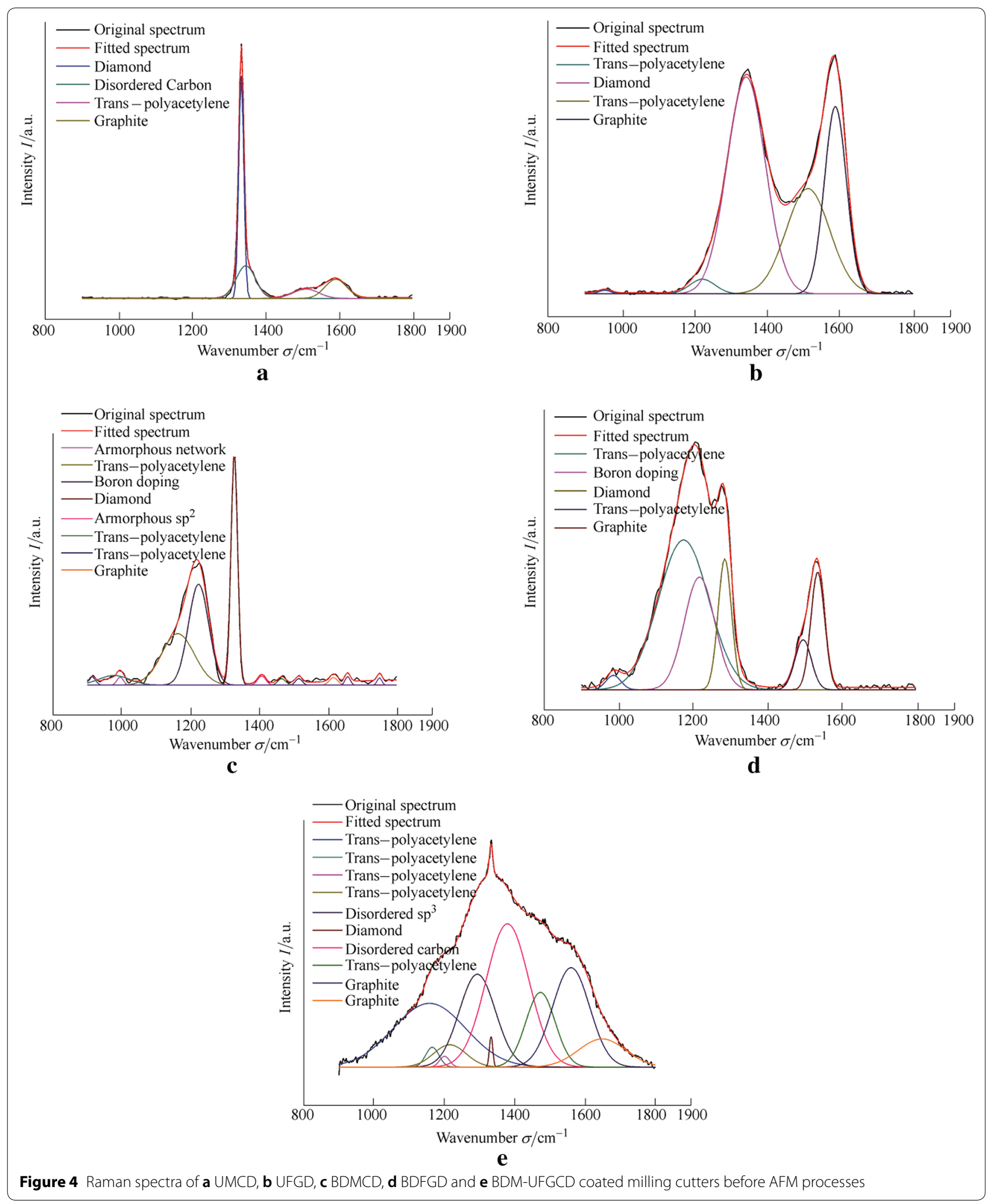


cutting-off milling cutters, which together with the influences of the AFM will all be discussed later.

\subsection{Effects of AFM}

Under the definite pressure of $15 \mathrm{MPa}$, the five different types of diamond coated milling cutters are all submitted to AFM, adopting variable cycle times. Variations of the surface roughness $R_{a}$ values on both the rake and flank faces of the different diamond coated milling cutters with the cycle time are all plotted in Figure 5, including some typical surface morphologies that are observed by the FESEM. It is to be expected that AFM processes can gradually reduce the $R_{a}$ values of all the polished surfaces, but some obvious differences exist between the different types of diamond coated milling cutters, or between the rake and flank faces of the same milling cutter.

Firstly, it is easily understood that for diamond coated specimens with a certain high initial surface roughness, the reduction of the $R_{a}$ value is more significant at the initial stage of AFM, mainly owing to the high material

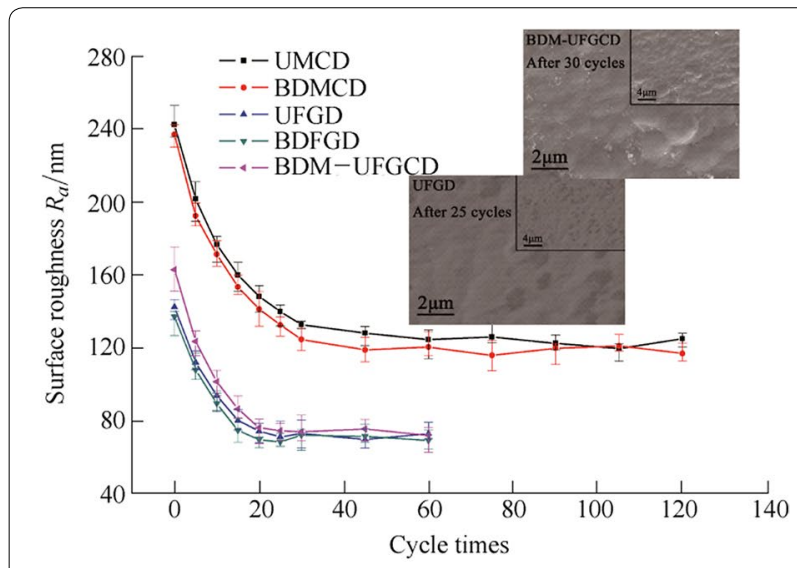

a

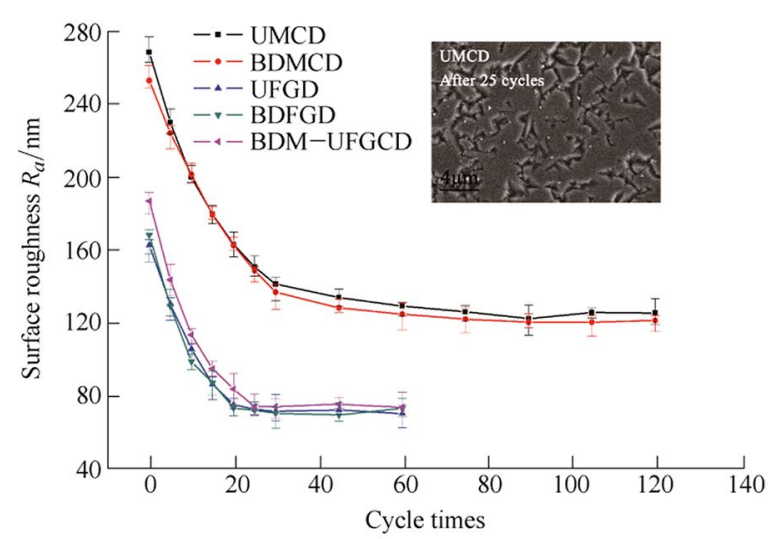

b

Figure 5 Variations of $R_{a}$ values on $\mathbf{a}$ the rake face and $\mathbf{b}$ the flank face of different diamond coated milling cutters with the cycle time, and some typical surface morphologies removal efficiency caused by the diamond particles in the paste on distinct peaks, edges and convex of as-synthesized diamond grains. With the surface smoothing, the polishing efficiency gradually decreases and approaches zero, indicating that the further polishing is impossible. There is a threshold of the attainable $R_{a}$ value for any diamond coated milling cutter, which is about $68-77 \mathrm{~nm}$ for the nano-sized film surfaces that is close to $R_{a}$ values of R-WC and F-WC specimens. Nevertheless, such the threshold is as high as $115-126 \mathrm{~nm}$ for micro-sized film surfaces. Moreover, the threshold for the BDMCD film (121 nm on average) is lower than that for the UMCD one (125 $\mathrm{nm}$ on average), and the threshold for the BDMUFGCD film (75 $\mathrm{nm}$ on average) is relatively higher than those for the single-layer UFGD film (72 $\mathrm{nm}$ on average) or BDFGD film (72 $\mathrm{nm}$ on average). In addition, because there is no obvious difference between the features of the same diamond films deposited on the rake and flank faces, such the thresholds for both the faces of the same diamond coated milling cutter are totally the same.

As indicated by the typical surface morphology of the AFM-UMCD specimen in Figure 5(b), after the sufficient AFM polishing, almost all the diamond protrusions are removed and about $90 \%$ of the film surface is smoothened, while there still exist a number of valleys between the diamond crystals. Under such the condition the polishing paste cannot provide enough grinding force for such the partly-polished diamond crystals, therefore the further polishing is useless and the $R_{a}$ value reaches the threshold. Moreover, because the grain size of the BDMCD film is a little smaller than that of the UMCD film, indicating that the residual valleys should be shallower, the threshold is relatively lower. Figure 5(a) gives the typical surface morphologies of the AFM-UFGD and AFM-BDM-UFGCD specimens after sufficient AFM, both of which present smooth surfaces, vague or partlyclear cauliflower-like nodules similar to the specimens before AFM, while without visible nano-sized diamond grains. Because the residual valleys between the nodules are much less than those on the surfaces of the UMCD and BDMCD films, corresponding thresholds of the $R_{a}$ values are much smaller. Due to the fact that the BDMUFGCD film has relatively larger nano-sized diamond grains than the single-layer FGD films, its threshold is a little larger.

Also due to the above reasons, the required cycle times for polishing the surfaces of the different diamond coated milling cutters to thresholds are distinctive. Just adopting the flank face as the example, for the UMCD film with the largest grain size, the highest initial $R_{a}$ value, the extremely high diamond purity and hardness, it takes almost 75 cycle times to reduce the $R_{a}$ value to the threshold. Owing to the refinement of the diamond grain 
caused by the boron doping and the slight reduction of the initial $R_{a}$ value, 60 cycle times of AFM can reduce its $R_{a}$ value to the threshold. The change of the grain size from micro to nano, along with the subsequent reduction of the initial $R_{a}$ value, diamond purity and hardness, contribute much to the polishing efficiency of the nano-sized surfaces. As a result, such the required cycle time for the three types of diamond films is 25 . In addition, it is found that for any of the diamond coated milling cutter, the required cycle time for the rake face is generally less than that for the flank face, because the grinding force provided of the polishing paste restricted in the spiral groove is relatively larger than that provided by the polishing paste around the flank face.

Besides the $R_{a}$ value, the radius of the peripheral cutting edge $r$ is also affected by AFM, as shown in Figure 6, including several typical cross-sectional morphologies of cutting-off milling cutters adopted for estimating such the $r$ values. It is apparent that the pretreatment process can increase the $r$ value significantly, since the alkali etching, acid etching and the grinding can all passivate the cutting edge of the well-prepared R-WC milling cutter. Afterwards, the deposition of the varieties of diamond films on the pretreated substrates, i.e., the "piling up" of the micro-sized or the nano-sized diamond crystals can slightly reduce the $r$ value, while as a whole, the combination of the indispensable pretreatment and the deposition of the diamond film can inevitably blunt the

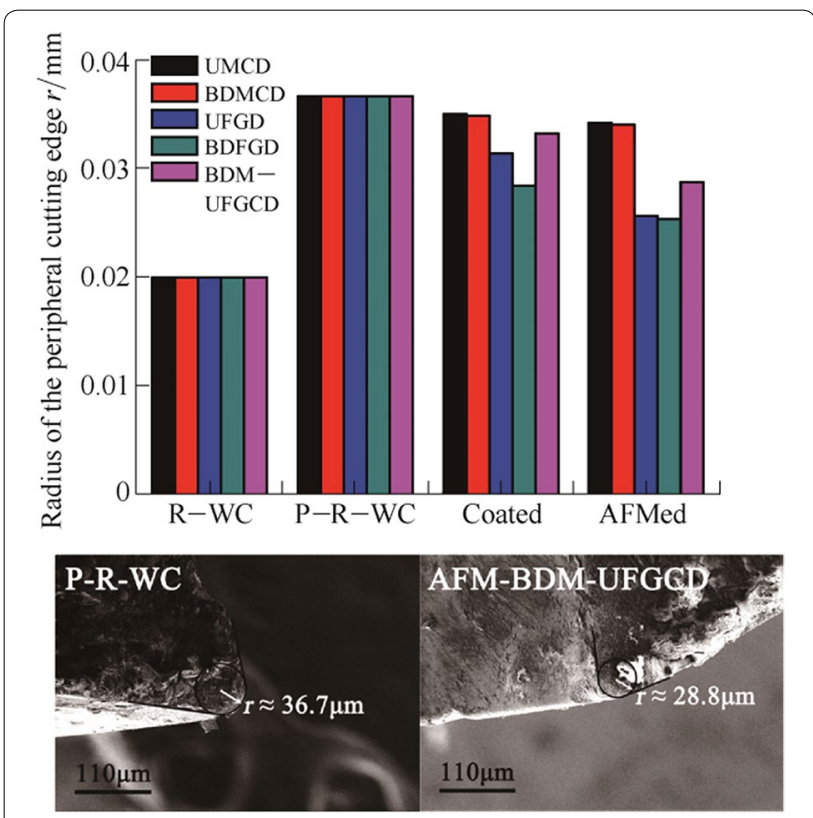

Figure 6 Radii of peripheral cutting edges of R-WC milling cutters before and after the pretreatment, together with the five different diamond coated milling cutters before and after sufficient AFM cutting edge. Under most of the conditions, it is believed that such the passivation of the cutting edge caused by the pretreatment is beneficial for the continued deposition of the diamond film and the lifetime elongation of the coated milling cutter, because it is difficult to guarantee the adhesion on the sharp cutting edge. However, the passivation of the cutting edge often means the deterioration of the machining quality. Coincidentally, it is additionally found that the AFM process can improve not only the surface smoothness but also the sharpness of the peripheral cutting edge with relatively large radius, especially for diamond coated milling cutters having nanosized diamond grains on the surfaces. After the sufficient AFM processes that can reduce the respective $R_{a}$ values to the thresholds, the $r$ value for the UFGD coated milling cutter slightly decreases from $31.4 \mu \mathrm{m}$ to $25.7 \mu \mathrm{m}$, and that for the BDFGD one from $28.4 \mu \mathrm{m}$ to $25.4 \mu \mathrm{m}$, and that for the BDM-UFGCD one from $33.2 \mu \mathrm{m}$ to 28.8 $\mu \mathrm{m}$. However, noteworthy is that even polished by AFM, all the $r$ values for the diamond coated milling cutters still cannot reach to as low as those for the R-WC specimen, let alone the F-WC specimen.

Another advantage of AFM adopted for polishing the diamond film is that it can avoid the graphitization and ensure the diamond purity as much as possible. It is known that when polishing the diamond materials by other techniques, such as mechanical, thermo-chemical and chemo-mechanical polishing, graphitization often occurs $[42,43]$, mainly owing to the instant high temperature and the chemical catalyst. It is acknowledged that the moderate graphitization is conducive to the polishing by reduce the surface hardness, while it inevitably deteriorates the wear resistance and some other excellent surface features of the diamond film. In the present investigation, for any type of the diamond film, the relative graphite content $G$, which is determined as the ratio of the intensity of the graphite peak to the total intensity of all the peaks in the Raman spectrum after the G-L deconvolution, hardly increases after AFM, as demonstrated by Figure 7 .

The $G$ is just adopted for approximately evaluating the graphitization, but not the exact graphite content in the diamond film, due to the neglect of different sensitivities of the Raman signal to the different carbon phases [44]. It is known that for the diamond films, especially for the MCD films with low initial graphite contents, the graphitization is obvious under some other polishing conditions. However, in the AFM process, the polished surface of the diamond coated milling cutter can only contact with the polishing paste made of the colloidal resin carrier, diamond particles, lubricant and the adherent agent, which hardly have catalytic function for the graphitization like the iron-group elements. Furthermore, because 

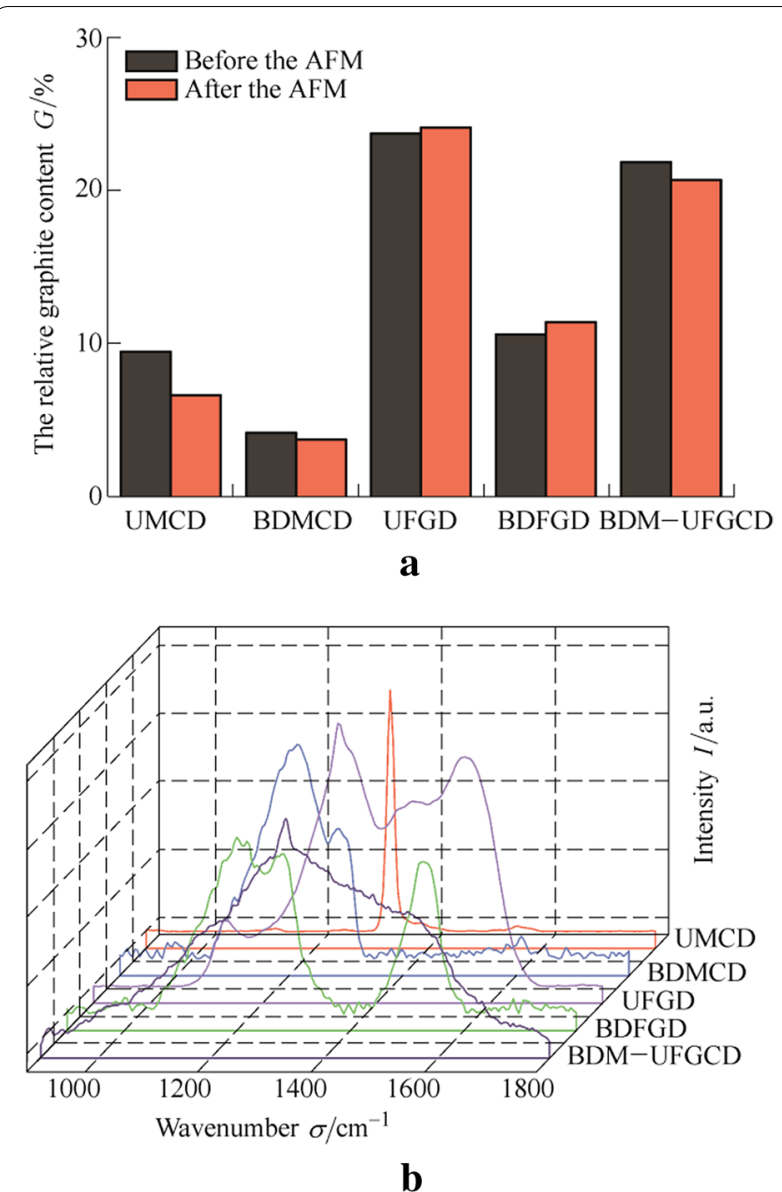

Figure 7 a The relative diamond purity $Q$ of different diamond coated milling cutters before and after AFM processes, and $\mathbf{b}$ Raman spectra of specimens after AFM

the interaction between the polishing paste and polished surface is not as severe as those in some other traditional polishing processes, so the grinding force of AFM is relatively small. Consequently, the temperature of the polished surface, which is measures as $30-150{ }^{\circ} \mathrm{C}$, is far below the graphitization temperature of the diamond film and the polishing temperatures in other techniques, such as thermo-chemical polishing, in which the temperature of the polished surface should be controlled as $450-900{ }^{\circ} \mathrm{C}$.

\subsection{Results of Cutting Tests}

The reduction of the surface roughness and the sharpening of the cutting edge of the diamond coated milling cutters directly reflect in as-measured cutting forces at the initial stages of the present peripheral finish-milling processes, as shown in Figure 8. The values of the total cutting forces $F$ in Figure 8(b) are all obtained by composing the directional cutting forces $F_{x}, F_{y}$ and $F_{z}$, all of which are calculated by averaging the cutting force signals in the

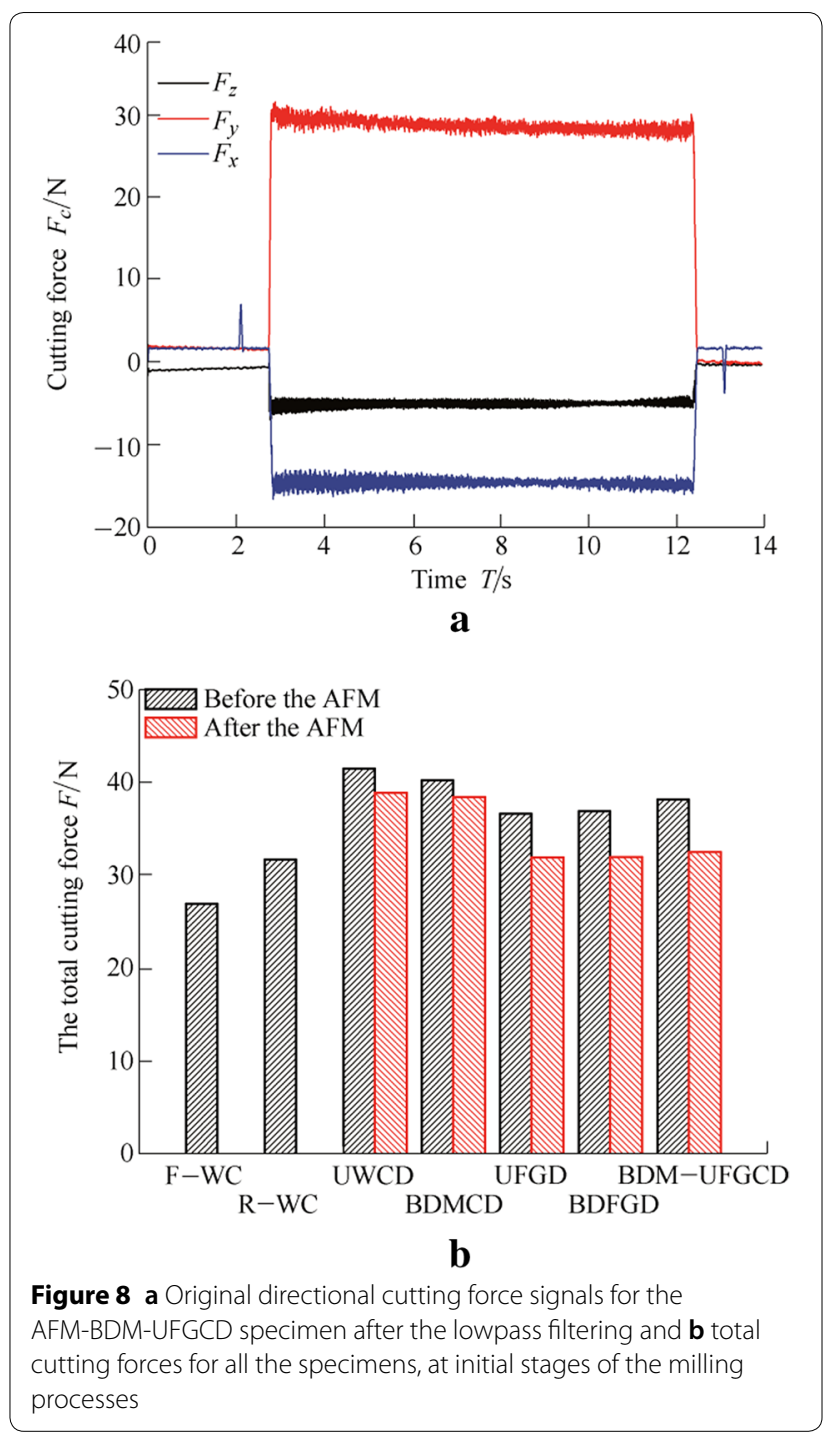

analyzed zone as exemplified in Figure 8(a). It is known that the cutting force originates from the resistance to elastic or plastic deformations in three deformation zones of the workpiece, and the frictional forces between the cutting tool and the workpiece or the chip. It is supposed that the reduction of the surface roughness of the rake and flank faces might reduce the coefficient of the friction (COF) between the diamond film and the $\mathrm{Al}$ alloy workpiece, attributed to the weakening of the plough effects caused by the diamond peaks and edges on the soft material, and thus reduce the frictional forces mainly between the milling cutter and the workpiece in the finish-milling of the $\mathrm{Al}$ alloy workpiece. Besides, the sharper the cutting edge, the lower the resistance to the deformation. In consequence, it is firstly found that the F-WC milling cutter owning rather sharp cutting edge and low surface roughness, shows a lower cutting force than the 


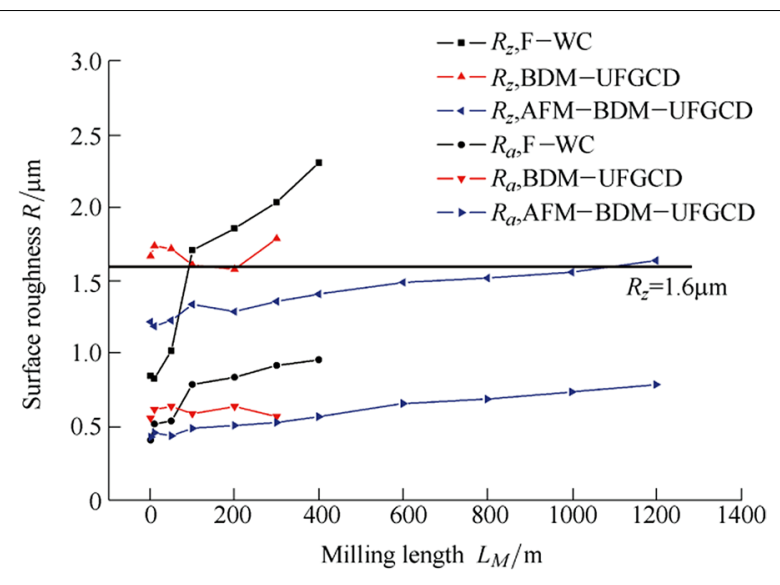

a

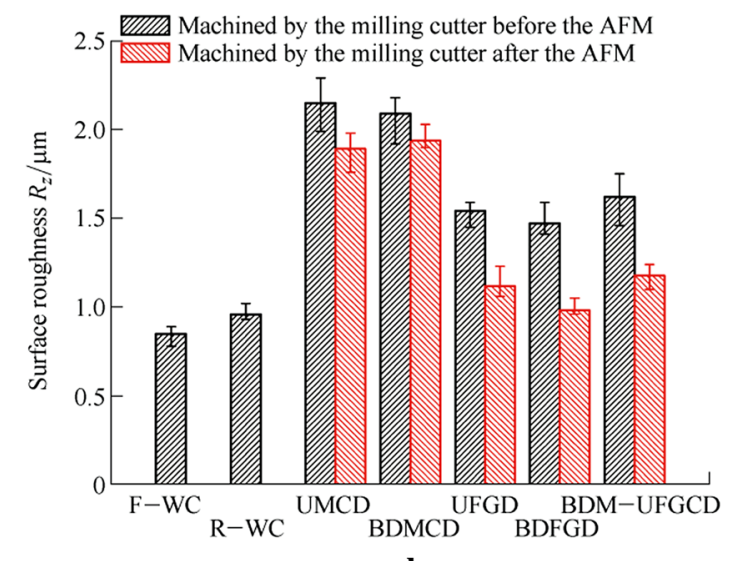

b

Figure 9 a Variations of both the $R_{a}$ and $R_{z}$ values of workpieces machined by three typical specimens with the milling length and b corresponding $R_{z}$ values of workpieces machined by all the specimens at initial stages of milling processes

R-WC one. Secondly, UMCD and BDMCD coated milling cutters perform much higher cutting forces than the uncoated R-WC one, attributed to either the increased surface roughness or the passivation of the cutting edge, but the UFGD, BDFGD and BDM-UFGCD coated milling cutters perform lower cutting forces than UMCD and BDMCD ones. Distinctly, AFM can reduce cutting forces of all the diamond coated milling cutters at different levels, obviously as a result of the re-smoothening of both the rake and flank faces, together with the resharpening of the cutting edges. Owing to the insufficient polishing on both the micro-sized surfaces and the rather limited resharpening of the cutting edges, the cutting forces provided by the AFM-UMCD and AFM-BDMCD specimens are still significantly higher than that provided by the $\mathrm{R}-\mathrm{WC}$ one. On the contrary, although surface roughness $R_{a}$ values and radii of cutting edges $r$ for the AFM-UFGD, AFM-BDFGD and AFM-BDM-UFGCD specimens are larger than those for the R-WC one, they show cutting forces approaching to that provided by the R-WC, due to the natural excellent tribological properties of nano-sized diamond films when sliding against soft $\mathrm{Al}$ alloy, such as the low COF [41].

When finish milling the $\mathrm{Al}$ alloy, the most intuitionistic criterion to evaluate the performance of the milling cutter is the surface quality of the workpiece, which is associated with not only the initial condition of the milling cutter, but also the wear or fracture in the machining process. Surface roughness $R_{a}$ and $R_{z}$ values of as-machined workpieces are both measured. It is well acknowledged that the $R_{a}$ value is the most commonly-used parameter, which can fully reflect micro-geometrical features of the surface. Besides, the $R_{z}$ value is also widely used for evaluating the surface quality of the $\mathrm{Al}$ alloy workpiece during the finish milling process, since it can reflect the existence and the severity of the surface texture caused by the milling cutter to a certain extent. The surface texture is one of the critical criteria for evaluating the machining quality of many $\mathrm{Al}$ alloy workpieces after the finish milling, such as the mobile phone shells, and such the surface texture is mostly parallel to the feed direction. As a result, when measuring the surface roughness by the surface profilometer, the scanning direction is selected to be perpendicular to the surface texture (the feed direction), and thus the $R_{z}$ value that can fully reflect the surface texture can be obtained.

In order to make full sense of the machining quality, failure mode and the tool lifetime of different specimens, in the present study, for each type of the specimen, milling tests are conducted on five different samples. Variations of both the $R_{a}$ and $R_{z}$ values of workpieces machined by three typical types of specimens (one of the five), including the F-WC and the BDM-UFGCD coated milling cutters before and after AFM, along with the milling lengths are shown in Figure 9(a). It is found that the surface quality of as-machined workpiece will gradually deteriorate, probably attributed to the gradual wear or even the fracture of the milling cutter. The $R_{z}$ value of as-machined workpiece at the initial stage, only associated with the initial condition of the perfect milling cutter, is adopted as the first criterion for evaluating the machining quality and comparing the performance of the different specimens. $R_{z}$ values of workpieces machined by all the specimens at initial stages are shown in Figure 9(b). It is known that the machining quality is influenced by the smoothness of the rake and flank faces, and the sharpness of the cutting edge of the milling cutter. In consequence, the workpiece machined by the F-WC milling cutter presents an initial $R_{z}$ value as low as $0.85 \mu \mathrm{m}$, while that of the workpiece machined by the R-WC one reaches $0.96 \mu \mathrm{m}$. After depositing various diamond films on the pretreated R-WC milling cutters, associated with the roughening of the rake 


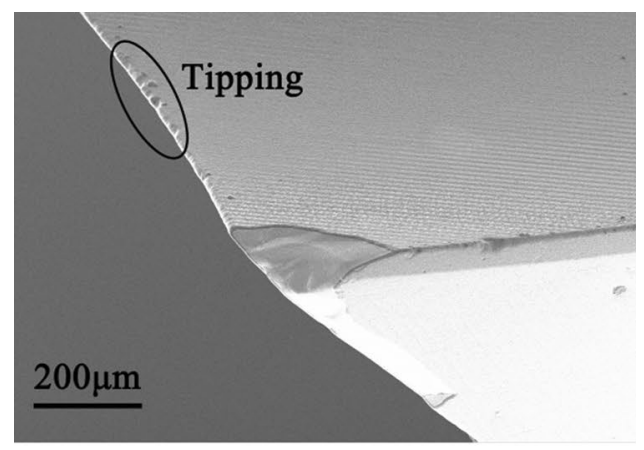

$\mathbf{a}$

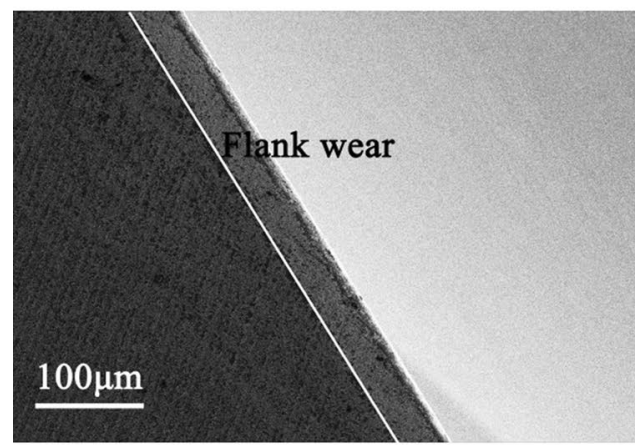

b

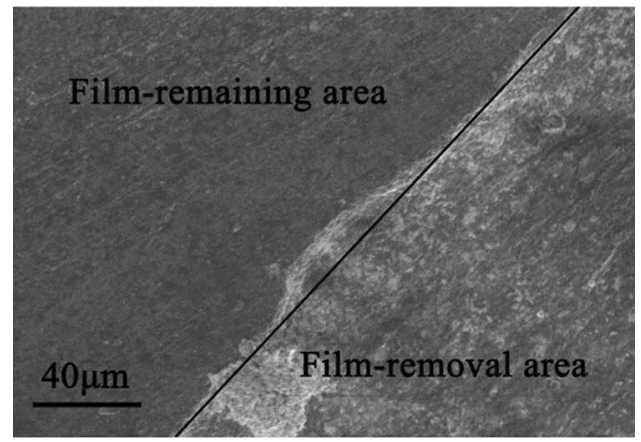

c

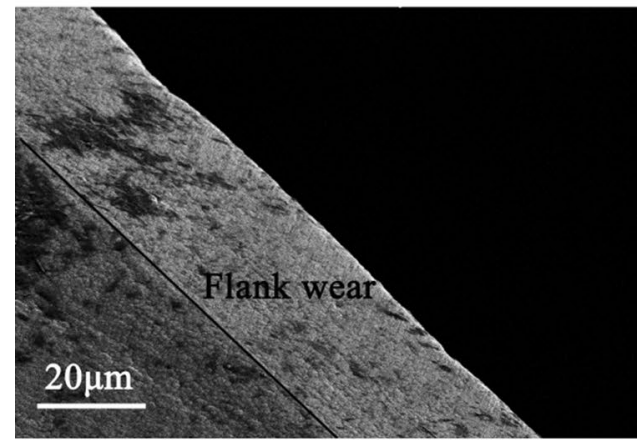

d

Figure 10 Typical wear or failure modes for typical specimens: a the abnormal but expected tipping of one F-WC specimen; $\mathbf{b}$ the normal flank wear of one F-WC specimen; $\mathbf{c}$ the film removal of the AFM-UFGD specimen; $\mathbf{d}$ the slow flank wear of the AFM-BDM-UFGCD specimen and flank faces, the passivation of cutting edges and subsequent increasing of cutting forces, the initial $R_{z}$ values of corresponding as-machined workpieces are all above $1.45 \mu \mathrm{m}$, which can even reach $2.10 \mu \mathrm{m}$ for the microsized diamond coated specimens. As expected, AFM can improve the machining quality of all the diamond coated milling cutters, while such the effects on the micro-sized ones are rather limited. As for three nano-sized diamond coated milling cutters after AFM, initial $R_{z}$ values of asmachined workpieces reduce to $0.98-1.18 \mu \mathrm{m}$, approaching to that machined by the R-WC milling cutter.

Noteworthy to be reiterated that the tool lifetime is defined as the milling length when the surface roughness $R_{z}$ value of as-machined workpiece reaches $1.6 \mu \mathrm{m}$. It is supposed that the deterioration of the machining quality along with the process of the milling test is induced by the wear or fracture of the milling cutter, but the failure mode cannot be uniformly determined. For example, for one of the F-WC samples corresponding to the line in Figure 9(a), the sharp increment of the $R_{z}$ value from $50 \mathrm{~m}$ to $100 \mathrm{~m}$ (the tool failure) is caused by the abnormal but expected tipping (as shown in Figure 10(a)), while for another F-WC sample, the $R_{z}$ value gradually increases with the normal flank wear of the milling cutter (as shown in Figure 10(b)), and the tool lifetime reaches $200 \mathrm{~m}$. Similar divergent failure phenomena also exist for the R-WC milling cutters, while the probability of the tipping failure reduces. Besides, it is found that the gradual flank wear of diamond coated milling cutters, either before or after AFM, is rather slow, attributed to the high hardness and wear resistance. As a result of the sufficient increment of the radii of the cutting edges, the tipping also hardly appears on any diamond coated milling cutter. Nevertheless, they will also fail in some other ways. For the UMCD, BDMCD, AFM-UMCD, AFM-BDMCD and BDM-UFGCD specimens, due to the high surface roughness of the rake and flank faces, and the large radii of the cutting edges, the machining quality at the initial stages cannot meet the requirements of the machining quality, indicating that they originally fail. As for the UFGD and BDFGD coated milling cutters before and after AFM, apparent film fracture and removal occur before the severe flank wear (as exemplified in Figure 10(c)), which have a close relationship with the relatively poor adhesion of the nano-sized diamond films [42] and act as the main failure modes. As for the AFMBDM-UFGCD specimen, the flank wear similar to F-WC and $\mathrm{R}-\mathrm{WC}$ specimens appears as the main failure mode (as shown in Figure 10d), which however is much slower.

Without regard to the specific failure mode, adopting the machining quality $\left(R_{z}>1.6 \mu \mathrm{m}\right)$ as the uniform criterion, tool lifetimes of different specimens, which are obtained by conducting milling tests on five different samples for each the specimen, are all listed in Table 4. 
Table 4 Tool lifetimes of different specimens

\begin{tabular}{|c|c|c|c|c|c|c|}
\hline \multirow[t]{2}{*}{ Specimen } & \multicolumn{6}{|c|}{ Tool lifetime $L_{T}(\mathrm{~m})$} \\
\hline & 1 & 2 & 3 & 4 & 5 & Average \\
\hline F-WC & 100 & 100 & 200 & 200 & 100 & 140 \\
\hline R-WC & 200 & 200 & 200 & 200 & 300 & 220 \\
\hline UMCD & 0 & 0 & 0 & 0 & 0 & 0 \\
\hline AFM-UMCD & 0 & 0 & 0 & 0 & 0 & 0 \\
\hline BDMCD & 0 & 0 & 0 & 0 & 0 & 0 \\
\hline AFM-BDMCD & 0 & 0 & 0 & 0 & 0 & 0 \\
\hline UFGD & 300 & 300 & 300 & 200 & 300 & 280 \\
\hline AFM-UFGD & 300 & 400 & 300 & 300 & 200 & 320 \\
\hline BDFGD & 300 & 400 & 400 & 400 & 300 & 360 \\
\hline AFM-UFGD & 400 & 600 & 300 & 300 & 400 & 400 \\
\hline BDM-UFGCD & 0 & 0 & 0 & 50 & 0 & 10 \\
\hline AFM-BDM-UFGCD & 1200 & 1000 & 1000 & 800 & 1200 & 1040 \\
\hline
\end{tabular}

Although the machining quality of the R-WC milling cutter is worse than that of the F-WC one, it performs longer tool lifetime, due to the lower probability of tipping failure dependent on the relatively rounder cutting edge. The tool lifetimes of the UMCD, AFMUMCD, BDMCD, AFM-BDMCD and BDM-UFGCD specimens are zero or almost zero, because they cannot meet the requirements of the machining quality at the very beginning stages of the milling processes. The UFGD and BDFGD coated milling cutters either before or after AFM show slightly prolonged tool lifetimes than the uncoated ones, because the rapid fracture and removal of the nano-sized diamond films associated with their poor adhesion will cause the deterioration of the machining quality, especially for the UFGD and BDFGD coated milling cutters before AFM, the machining quality of which approaches the threshold value at the very beginning stages $\left(R_{z}=1.54 \mu \mathrm{m}\right.$ for UFGD and $R_{z}=1.47$ $\mu \mathrm{m}$ for BDFGD). It is proved that the boron doping can enhance the adhesion between the diamond film and the substrate, and there are favorable mechanical interlocks between micro-sized diamond grains and the substrate [45], therefore, the BDM-UFGCD film has not only low surface roughness but also nice adhesion. It is speculated that the AFM hardly influences the adhesion of as-deposited diamond films, so the AFM-BDM-UFGCD specimen presents a tool lifetime almost four times longer than the $\mathrm{R}-\mathrm{WC}$. Considering that the AFM-BDM-UFGCD specimen can provide favorable machining quality $\left(R_{z}=1.18\right.$ $\mu \mathrm{m})$ approaching to the uncoated milling cutters $\left(R_{z}=\right.$ $0.85 \mu \mathrm{m}$ for F-WC and $R_{z}=0.96 \mu \mathrm{m}$ for R-WC), and it is efficient to polish its surface by AFM, the BDM-UFGCD coated milling cutter after AFM is recognized as an important candidate for finish milling the $\mathrm{Al}$ alloy.

\section{Conclusions}

1. The pretreatment and the coverage of diamond films, especially micro-sized diamond films, apparently increase the surface roughness of both the rake and flank faces, and reduce the radii of the cutting edges.

2. The AFM can re-reduce the surface roughness of the rake and flank faces of the diamond coated milling cutter, and re-sharpen the cutting edge. It is the first time that the AFM is proposed, studied and applied for post-processing the diamond coated complicated cutting tool.

3. It is much more convenient and efficient to finish the surfaces of the nano-sized diamond coated milling cutters, and resharpen their cutting edges. Moreover, the AFM can avoid the graphitization and ensure the diamond purity as much as possible.

4. Attributed to the reduction of the surface roughness and the radii of cutting edges, the diamond coated milling cutters after AFM present lower cutting forces and improved machining quality. Additionally taking the improved adhesion and the much prolonged tool lifetime into considerations, the AFMBDM-UFGCD specimen is believed as an important candidate for the peripheral finish-milling of the $\mathrm{Al}$ alloy.

\section{Authors' Contributions}

$\mathrm{X}-\mathrm{CW}$ was in charge of the whole trial and wrote the manuscript; C-CW assited with deposition experiments; C-YW assited with cutting tests; F-HS assited with the in-depth discussions on mechanisms. All authors read and approved the final manuscript. 


\section{Authors' Information}

Xin-Chang Wang, born in 1988, is currently a post doctor at School of Mechanical Engineering, Shanghai Jiao Tong University, China. He received his doctor degree from Shanghai Jiao Tong University, China, in 2015. His research interests include the deposition, post-treatment and application of the diamond films.

Cheng-Chuan Wang, born in 1991, is currently a PhD candidate at School of Mechanical Engineering, Shanghai Jiao Tong University, China. His research interests include the textured growth and application of high-performance diamond films.

Chang-Ying Wang, born in 1990, is currently a PhD candidate at School of Mechanical Engineering, Shanghai Jiao Tong University, China. His research interests include the growth and application of monocrystal diamond particles, and the fabrication of CVD abrasive disks.

Fang-Hong Sun, born in 1965, is currently a professor at School of Mechanical Engineering, Shanghai Jiao Tong University, China. His research interests include the fabrication, modification and application of diamond films, the cutting and grinding.

\section{Competing Interests}

The authors declare that they have no competing interests.

\section{Funding}

Supported by National Natural Science Foundation of China (Grant No. 51275302), China Postdoctoral Science Foundation Special Funded Project (Grant No. 2016T90370), and China Postdoctoral Science Foundation (Grant No. 2015M580327)

\section{Publisher's Note}

Springer Nature remains neutral with regard to jurisdictional claims in published maps and institutional affiliations.

Received: 2 September 2016 Accepted: 9 November 2018

Published online: 21 November 2018

\section{References}

[1] C Martini, A Morri. Face milling of the EN AB-43300 aluminum alloy by PVD- and CVD-coated cemented carbide inserts. International Journal of Refractory Metals and Hard Materials, 2011, 6(29): 662-673.

[2] BT Lin, C C Kuo. Application of an integrated RE/RP/CAD/CAE/CAM system for magnesium alloy shell of mobile phone. Journal of Materials Processing Technology, 2009, 6(209): 2818-2830.

[3] T J Skingle, RW Thompson. Machining of aluminum alloys. Journal of Applied Metalworking, 1980, 2(1): 76-78.

[4] Bin Shen, Fang-Hong Sun, Hong-Guo Xue, et al. Study on fabrication and cutting performance of high quality diamond coated PCB milling tools with complicated geometries. Surface Engineering, 2009, 1(25): 70-76.

[5] A Kopf, S Feistrizer, K Udier. Diamond coated cutting tools for machining of non-ferrous metals and fibre reinforced polymers. International Journal of Refractory Metals and Hard Materials, 2006, 5(24): 354-359.

[6] Jian-Guo Zhang, Liang Wang, Bin Shen, et al. Fabrication and cutting performance of CVD diamond coated inserts with different coating thickness in dry turning aluminum alloy. Advanced Materials Research, 2012, (497): 73-77.

[7] J M Oomen, J Eisses. Wear of monocrystalline diamond tools during ultraprecision machining of nonferrous metals. Precision Engineering, 1992, 4(14): 206-218.

[8] TSugano, K Takeuchi, T Goto, et al. Diamond turning of an aluminum alloy for mirror. CIRP Annals - Manufacturing Technology, 1987, 1(36): 17-20.

[9] C Kalyan, G L Samuel. Cutting mode analysis in high speed finish turning of AIMgSi alloy using edge chamfered PCD tools. Journal of Materials Processing Technology, 2015, (216): 146-159.

[10] D Ishimarua, M Tougea, H Mutaa, et al. Burr suppression using sharpened PCD cutting edge by ultraviolet-ray irradiation assisted polishing. Procedia CIRP, 2012, 1(1): 184-189.
[11] E Cappelli, F Pinzari, P Ascarelli, et al. Diamond nucleation and growth on different cutting tool materials: influence of substrate pre-treatments. Diamond and Related Materials, 1996, 3-5(5): 292-298.

[12] B Denkena, J Koehler, M Rehe. Influence of the honed cutting edge on tool wear and surface integrity in slot milling of $42 \mathrm{CrMo} 4$ steel. Procedia CIRP, 2012, 1(1): 190-195.

[13] F A Alimeida, F J Oliveira, M Sousa, et al. Machining hardmetal with CVD diamond direct coated ceramic tools: effect of tool edge geometry. Diamond and Related Materials, 2005, 3-7(14): 651-656.

[14] D G Bhat, G G Johnson, A P Malshe, et al. A preliminary investigation of the effect of post-deposition polishing of diamond films on the machining behavior of diamond-coated cutting tools. Diamond and Related Materials, 1995, 7(4): 921-929.

[15] K Saijo, M Yagi, K Shibuki, et al. Improvements in adhesive strength and cutting performance of diamond-coated tools. Surface and Coatings Technology, 1991, 1-3(47): 646-653.

[16] J Oakes, XX Pan, R Haubner, et al. Chemical vapour deposition diamond coatings on cemented carbide tools. Surface and Coatings Technology, 1991, 1-3(47): 600-607.

[17] P K Sen. CVDITE-a new type of cutting tool insert. Industrial Diamond Review, 1992, 552(52): 228-230.

[18] J Rech, Y C Yen, M J Schaff, et al. Influence of cutting edge radius on the wear resistance of PM-HSS milling inserts. Wear, 2005, 7-12(259): 1168-1176.

[19] E Uhlmann, S Richarz, V Mihotovic. Substrate pre-treatment of cemented carbides using abrasive flow machining and laser beam ablation. Production Engineering, 2009, 1(3): 81-86.

[20] C D Torres, P J Heaney, A V Sumant, et al. Analyzing the performance of diamond-coated micro end mills. International Journal of Machine Tools and Manufacture, 2009, 7-8(49): 599-612.

[21] F Qin, Y K Chou, D Nolen, et al. Coating thickness effects on diamond coated cutting tools. Surface and Coatings Technology, 2009, 6-7(204): 1056-1060.

[22] CT Kuo, C R Lin, H M Lien. Origins of the residual stress in CVD diamond films. Thin Solid Films, 1996, 96(290): 254-259.

[23] Xin-Chang Wang, Jian-Guo Zhang, Fang-Sun Sun, et al. Investigations on the fabrication and erosion behavior of the composite diamond coated nozzles. Wear, 2013, 1-2(304): 126-137.

[24] Xin-Chang Wang, Zi-Chao Lin, Tao Zhang, et al. Fabrication and application of boron-doped diamond coated rectangular-hole shaped drawing dies. International Journal of Refractory Metals and Hard Materials, 2013, 4(41): 422-431.

[25] Fang-Hong Sun, Zhi-Ming Zhang, Ming Chen, et al. Improvement of adhesive strength and surface roughness of diamond films on Cocemented tungsten carbide tools. Diamond and Related Materials, 2003, 3-7(12): 711-718

[26] Zhi-Ming Zhang, Xian-Chang He, He-Sheng Shen, et al. Pre-treatment for diamond coatings on free-shape WC-Co tools. Diamond and Related Materials, 2000, 9-10(9): 1749-1752.

[27] N Dilawar, R Kapil, Brahamprakash, et al. Adhesion enhancement of diamond coatings on WC tools by high energy ion irradiation. Thin Solid Films, 1998, 1-2(323): 163-169.

[28] S Silva, V P Mammana, M C Salvadori, et al. WC-Co cutting tool inserts with diamond coatings. Diamond and Related Materials, 1999, 10(8): 1913-1918.

[29] F Xu, J H Xu, M F Yuen, et al. Adhesion improvement of diamond coatings on cemented carbide with high cobalt content using PVD interlayer. Diamond and Related Materials, 2013, 2(34): 70-75.

[30] Xin-Chang Wang, Jian-Guo Zhang, Bin Shen, et al. Erosion mechanism of the boron-doped diamond films of different thicknesses. Wear, 2014 1-2(312): 1-10.

[31] Liang Wang, Xue-Lin Lei, Bin Shen, et al. Tribological properties and cutting performance of boron and silicon doped diamond films on Cocemented tungsten carbide inserts. Diamond and Related Materials, 2013, 3(33): 54-62

[32] Q P Wei, Z M Yu, M N R Ashfold, et al. Synthesis of micro- or nano-crystalline diamond films on WC-Co substrates with various pretreatments by hot filament chemical vapor deposition. Applied Surface Science, 2010 13(256): 4357-4364

[33] Jian-Guo Zhang, Tao Zhang, Xin-Chang Wang, et al. Simulation and experimental studies on substrate temperature and gas density field in 
HFCVD diamond films growth on WC-Co drill tools. Surface Review and Letters, 2013, 2(20): 1350020.

[34] R Hessmer, M Schreck, S Geier, et al. The influence of the growth-process on the film texture of epitaxially nucleated diamond on silicon(001). Diamond and Related Materials, 1995, 4(4): 410-415.

[35] Xin-Chang Wang, Xiao-Tian Shen, Tian-Qi Zhao, et al. Growth time optimization of fine grained diamond coated drills for machining CFRP. Materials Science Forum, 2016, (836-837): 333-339.

[36] Xue-Lin Lei, Liang Wang, Bin Shen, et al. Micro drill with variations in thickness of diamond coating. Surface Engineering, 2016, 3(32): 165-171.

[37] Tao Zhang, Liang Wang, Fang-Hong Sun, et al. The effect of boron doping on the morphology and growth rate of micron diamond powders synthesized by HFCVD method. Diamond and Related Materials, 2013, 6(40): 82-88.

[38] T Liu, D Raabe. Influence of nitrogen doping on growth rate and texture evolution of chemical vapor deposition diamond films. Applied Physics Letters, 2009, 2(94): 021119.

[39] E Gheeraert, P Gonon, A Deneuville. Effect of boron incorporation on the "quality" of MPCVD diamond films. Diamond and Related Materials, 1993, 5-7(2): 742-746.

[40] S Schwarz, S M Rosiwal, M Frank, et al. Dependence of the growth rate, quality, and morphology of diamond coatings on the pressure during the CVD-process in an industrial hot-filament plant. Diamond and Related Materials, 2002, 3-6(11): 589-595.

[41] K K Kar, N L Ravikumar, P B Tailor, et al. Performance evaluation and rheological characterization of newly developed butyl rubber based media for abrasive flow machining process. Journal of Materials Processing Technology, 2009, 4(209): 2212-2221.

[42] S E Grillo, J E Field, F M van Bouwelen. Diamond polishing: the dependency of friction and wear on load and crystal orientation. Journal of Physics D: Applied Physics, 2000, 8(33): 985-990.

[43] T Schuelke, T A Grotjohn. Diamond polishing. Diamond and Related Materials, 2013, 2(32): 17-26.

[44] M Bernard, A Deneuville, P Muret. Non-destructive determination of the boron concentration of heavily doped metallic diamond thin films from Raman spectroscopy. Diamond and Related Materials, 2004, 2(13): 282-286.

[45] Xin-Chang Wang, Jian-Guo Zhang, Bin Shen, et al. Fracture and solid particle erosion of micro-crystalline, nano-crystalline and boron-doped diamond films. International Journal of Refractory Metals and Hard Materials, 2014, (45): 31-40.

\section{Submit your manuscript to a SpringerOpen ${ }^{\odot}$ journal and benefit from:}

- Convenient online submission

- Rigorous peer review

- Open access: articles freely available online

- High visibility within the field

- Retaining the copyright to your article

Submit your next manuscript at $\gg$ springeropen.com 